UCRL-86083 Rev.-1

PREPRINT

DEVELOPMENT AND APPLICATION OF A HYDROTHERMAL MODEL FOR THE SALTON SEA GEOTHERMAL FIELD, CA

\author{
P. Kasameyer \\ L. Younker \\ J. Hanson
}

This Paper was Prepared for Submittal to Bulletin of. the Geological Society of America

January 4, 1984

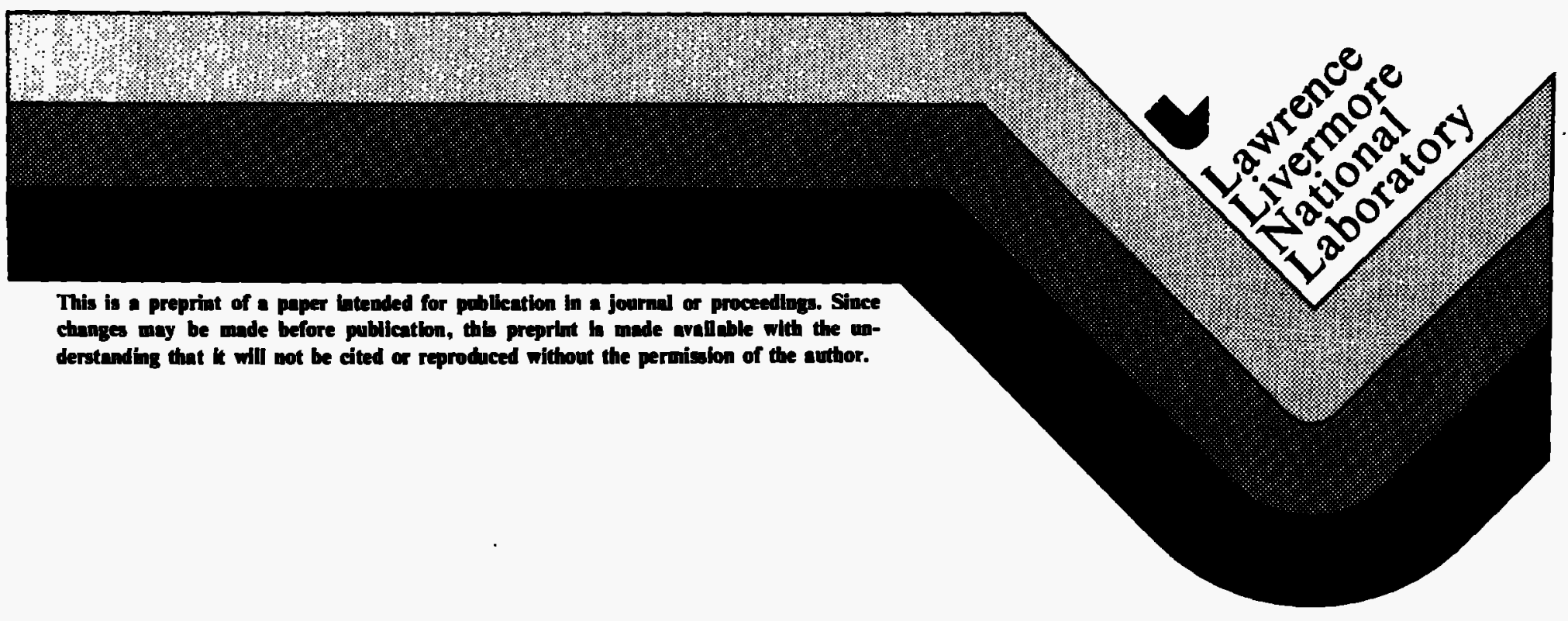




\section{DISCLAIMER}

This document was prepared as an account of work sponsored by an agency of the United States Government. Neither the United States Government nor the University of California nor any of their employees, makes any warranty, express or implied, or assumes any legal liability or responsibility for the accuracy, completeness, or usefulness of any information, apparatus, product, or process disclosed, or represents that its use would not infringe privately owned rights. Reference herein to any specific commercial products, process, or service by trade name, trademark, manufacturer, or otherwise, does not necessarily constitute or imply its endorsement recommendation, or favoring of the United States Government or the University of California. The views and opinions of authors expressed herein do not necessarily state or reflect those of the United States Government or the University of California, and shall not be used for advertising or product endorsement purposes. 


\title{
DEVELOPMENT AND APPLICATION OF A HYDROTHERMAL MODEL FOR THE SALTON SEA GEOTHERMAL FIELD, CALIFORNIA*
}

\author{
P. W. Kas ameyer \\ L. W. Younker \\ J. M. Hanson
}

This paper was prepared for submittal to the Bulletin of the Geological Society of America.

* Work performed under the auspices of the U.S. Department of Energy by Lawrence Livermore. National Laboratory under Contract W-7405-Eng-48. 

Development and Application of a Hydrothermal Model for the Salton Sea Geothermal Field, California

PAUL W. KASAMEYER

LELAND W. YOUNKER

JONATHAN M. HANSON*
Earth Sciences Division, University of California

Lawrence Livermore National Laboratory,

Livermore, California 94550 (U.S.A.)

ABSTRACT

A simple lateral flow model adequately explains many of the features associated with the Salton Sea Geothermal. Field. Earthquake swarms, a magnetic anomaly, and aspects of the gravity anomaly are all indirect evidence for the igneous activity which is the ultimate source of heat for the system. . Heat is transferred from this area of intrusion by lateral spreading of hot water in a reservoir beneath an impermeable cap rock.

A two dimensional analytic model encompassing this transport mechanism matches general features of the thermal anomaly and has been used to estimate the age of the presently observed thermal system. The age is calculated by minimizing the variance between the observed surface heat-flow data and the model. Estimates of the system age for this model range from 3,000 to 20,000 years.

*Present address:

Terra Tek Research

Salt Lake City, Utah 84108 


\section{INTRODUCTION}

The Salton Sea Geothermal Field (SSGF) lies with in one of the largest and hottest hydrothermal systems in the world (see Fig. 1). Like other hydrothermal systems in the Salton Trough, this field is apparently a direct product of extension and resulting magmatic intrusion associated with the right lateral transform boundary of the western margin of the North American plate (Lomnitz and others, 1970; Elders and others, 1972). Wherever faults veer to the right in this region, local zones of crustal extension occur and may allow magma to intrude into the crust and act as a heat source to drive hydrothermal systems. A few small volcanic buttes on the southeastern shore of the Salton Sea are direct surface evidence of the location of one of these zones of intrusion.

The geothermal field southeast of the buttes has been studied by several surface geophysical methods and by deep and shallow drilling. Many papers have summarized aspects of the geology, geochemistry and geophysics of the field (e.g. Helgeson, 1968; Muffler and White, 1969; Randall, 1974; Robinson .' and others, 1976; McDowell and Elders, 1980; Bird and Norton, 1981; Younker and others, 1982). The fluid-flow patterns and heat-transfer mechanisms by which heat is carried up from the region of intrusion has not been described in any detail. We have used the extensive data set to develop a hydrothermal system model which describes the heat transfer from the zone of intrusion.

In this paper, the evidence for the nature and location of the heat source is reviewed. It is concluded that mafic and silicic dikes intrude into the area of offset between the Brawley and San Andreas faults and supply heat to the system. Next, conclusions about the distribution of permeability around the heat source are reviewed. Strong barriers to vertical fluid flow preclude large-scale vertical convection cells with in the explored region. observations consistent with high lateral permeability support a model in 
which the system acts as a flow-through water heater with fluid cooling as it carries heat laterally from the heat source. Finally, this conceptual model is used as a basis for developing an analytical model of lateral convective transfer of heat in a reservoir bounded vertically by relatively impermeable conductive zones. The analytical model is developed and compared.to geophysical and geothermal field measurements. The model produces temperatures which match observations, and it is simple enough to allow evaluation of analytical results for a broad range of parameters so that bounds are placed on the nature of the hydrothermal system. In particular, the model is used to estimate age and flow rates and to rigorously evaluate the limitations in our understanding of the system.

\section{CONCEPTUAL MODEL FOR THE GEOTHERMAL SYSTEM}

\section{Heat Source}

Lomnitz and others (1970) suggested that the tectonic framework in the northern Gulf of California and Salton Trough could be approximated by a series of transform faults connected by spreading centers. They postulated that active ridge segments account for the geothermal anomalies near Cerro Prieto and the Salton Buttes. Elders and others (1972) expanded and refined the model and proposed that active spreading centers occur in tensional zones, or rhombochasms, between en echelon strike slip faults. They postuiate spreading centers near the Salton Buttes, Brawley, and Cerro Prieto. Elders and Biehler (1975) and Hill and others (1975) label these areas "leaky transform faults" in order to emphasize that the dominant movement in the valley is strike slip with the "spreading" taking place in a rather diffuse zone of offset strike slip faults.

Because of the thick sedimentary cover in the trough, the rhombochasm leaky transform theory is difficult to verify. Howard (1976) has provided 
field support for the theory by studying the analogous San Jacinto fault system. In the Red Mountain area of the San Jacinto Mountains. Howard has noted the presence of several northeast-trending extensional faults joining the Coyote Creek fault with the northwest-trending San Jacinto fault. The extension faults are steep normal or reverse faults near the surface but become moderate-to-shallow-dipping normal faults at depth. Sharp (1967) related the faults to the dying out of the Coyote Creek fault. The right lateral movement near its terminus is partiy absorbed by pervasive deformation of the crystalline rocks and partly absorbed by the northwest-southeast extensional movement along the faults. By analogy, it might be expected that the region connecting the Banning-Mission Creek section of the San Andreas fault and the Brawley fault should be cut by extensional faults producing the "leaky transform system" described by Elders and Biehler (1975) (Fig. 1). Earthquake data, well observations, magnetic anomalies, and a recent seismic refraction survey provide further support for the leaky transform model. The area surrounding the Salton Sea Geothermal field has been the site: of several earthquake swarms. Thatcher and Brune (1971) summarized four swarm sequences which occurred in 1963, 1965, 1968, and 1969 in the Obsidian Butte area. Johnson and Hadley (1976) used observations of an earthquake swarm to locate an offset of the Imperial fault near Brawley. Gilpin and Lee (1978) used a portable seismic network to locate activity on the north end of the Brawley fault near obsidian butte. They characterize the seismicity of the area as "two to three events per day $\left(M_{L}<3.0\right)$ commonly occurring in clusters along with intermittent swarm activities." First-motion studies of two swarms indicate both normal faulting and strike slip faulting in an area between two offset segments of the Brawley fault. McEuen and others (1977) analyzed earthquake occurrence data in the Imperial Valley and concluded that the main stress-release mechanism near the Salton Sea Field is strike slip 
movement. They confirmed, however, that localized events (e.g., the swarm of 1963 reported by Thatcher and Brune). involved tensional strain release. Thus, seismic observations support a dominantly strike slip motion occasionally interrupted by.tensional strain release in the inferred leaky transform region. Hypocenters associated with the Brawley swarm vary between 4 and $8 \mathrm{~km}$ (Johnson and Hadley, 1976), placing the depth range from somewhat above the crystalline basement to several kilometers into the crystalline basement.

Several 1 ines of direct and indirect evidence indicate that the inferred leaky transform system is associated with the intrusion of dikes and sills into the basement complex and, perhaps, into the sedimentary section. Robinson and others (1976) report that samples of subsurface igneous rock were recovered from at least four wells within the field. Mafic and silicic rock, interpreted to be thin dikes and sills, were present at depths ranging from approximately 1 to $2 \mathrm{~km}$. Indirect evidence for pervasive intrusion is provided by the magnetic and gravity anomalies. Griscom and Muffler (1971) have interpreted the elongated magnetic anomaly to be due to 10-20\% dike, " material which is less than a kilometer from the surface. Biehler and Combs (1972) report that at least a portion of the gravity anomaly is probably due to the emplacement of igneous rocks into the sedimentary pile. Seismic refraction data (Frith 1978) indicates anomalously high-velocity material near the surface of this region. This is consistent with regions containing both hydrothermally altered sediments and igneous intrusions.

The earthquakes, magnetic anomaly, gravity anomaly, and, presumably, the heat-flow anomaly are all believed to be related to the intrusion of dikes into the sedimentary section along zones of extension between offset $r$ ight lateral faults. Hill (1977) has formalized the relationship between earthquake swarms and dike intrusion and has applied it to the Brawley swarms of June 1973 and January 1975. In his theory, shear failure occurs along 
fault planes connecting tips of offset dikes.

Lachenbruch and others (1976) and Lachenbruch and Sass (1978) have made calculations of heat and mass budgets for somewhat similar volcanic centers. They have proposed that rapid local extension (e.g., that which occurs in the leaky transform system) controls the passive rise of basalt through the lithosphere and thereby controls the location of volcanic centers. In the following section it is shown that the dominant mechanism of heat transfer away from this zone of intrusion can be inferred from the characteristics of the thermal field.

Heat Transfer - Mechanisms

Most of the heat and mass transfer models constructed for hydrologic systems with in the Salton Trough have features in common. (Bird and Elders, 1975; Swanberg, 1975; B1ack, 1975; Noble, and others; 1977; Kassoy and Goyal, 1979; Riney and others, 1979; Goyal and Kassoy, 1980; and Elders, and others, 1980: Elders and others, 1983). These models incorporate fluid heating at i' depth, percolation of fluid up a high permeability fracture or fault zone, lateral spreading of hot water beneath impermeable layers, and conduction dominated heat transfer from the hot fluid through the cap to the surface. Riney and others (1977) present a model for the Salton Sea Geothermal Field which is different from these cited above. Hot water rises throughout the system, and is swept northward by the regional hydrologic flow. In our paper, we develop a simple model to calculate the thermal effects of the lateral flow feature of many models discussed above. These effects are compared to data from the Salton Sea Geothermal Field.

In a previous paper (Younker, and others, 1982), the observed temperature-depth profiles in and around the Salton Sea Geothermal Field were analyzed. Conclusions were drawn about heat transfer mechanisms in different 
parts of the system. Those conclusions are reviewed here. We divided the area on the southeast flank of the field into three roughly concentric zones (Fig. 2). Zone $A$, nearest to the center of the geothermal field, is marked by nearly constant, moderately high temperature gradient in the upper few hundred meters above a nearly isothermal zone. Zone B, most distant from the center, is characterized by a much lower, nearly constant temperature gradient consistent with the normal regional gradient. Zone $C$ is a transition region with low near-surface gradient and increasing temperature gradient at greater depth. The broad uniform gradient region of Zone $A$ and the rapid transition to Zone $B$ are readily apparent in Fig. 2. Figure 3 shows examples of temperature profiles from the interior Zone $A$ and the transition Zone $C$. Analysis of equilibrium-temperature profiles for the wells in the Salton Sea Geothermal Field indicates that heat-transfer mechanisms can be qualitatively described in terms of a three-layer system. The uppermost layer is a thermal cap. The upper portion of the cap is impermeable to fluid flow and characterized by a high thermal gradient consistent with conduction. The : lower part of the thermal cap is still relatively impermeable to vertical flow, but an increase in the percentage of higher conductivity sand produces a reduced temperature gradient. The relationship between this "thermal" cap, and Randall's (1974) lithologic cap is discussed in Younker and others, 1982. Layer 2 is a permeable aquifer characterized by low thermal gradients consistent with some form of convective flow of pore fluid. Little is known about the third layer, which is assumed to be an impermeable base. .

With in the permeable aquifer, vertical permeability is low and horizontal permeability is high. This distribution of permeability suggests that lateral flow of pore fluid is the dominant mass-transport mechanism within the aquifer. Within this layer, the rock matrix in Zone $A$ has been heated to a fairiy uniform temperature and the oniy vertical heat transfer is steady-state 
heat flow upward through the cap which has reached a steady-state temperature profile. In the previous paper, we speculated that the fluid in the aquifer flows from Zone A toward Zone B. Outside Zone A, the fluid cools by losing heat to the rock matrix and the transient heat flow in the cap may not have reached the surface. Farther from the source, in Zone B, cooled fluid flows in equilibrium with the initial temperature distribution in the aquifer and cap.

In this paper, we propose to learn about the evolution of the hydrothermal system from the heat flow observations using this relatively simple model involving only lateral flow of fluid through a porous aquifer. This is an unusual approach to modeling a geothermal system. Usually one presumes a set of known initial physical conditions, such as temperature and permeability distributions, and calculates the resulting fluid flow patterns. For example, Lau (1980) has used this approach to model the SSGF.

This type of modeling approach is very useful for solving the "forward" problem: i.e., given initial conditions and a specified intrusion, what is $i$ the resulting thermal field? For several reasons it is not so useful for "inverting" the observed temperatures to determine the initial conditions (Kasameyer, and others, 1983).

1) The observed data in the SSGF could be entirely within the zone of relatively uniform horizontal flow, and therefore not sample a very large part of the overall system modeled.

2) Dramatically different starting models produce very similar flow patterns in this upper part of the system. Consequently many of the parameters which are necessary to specify the complete model are undeterminable from the ayailable data.

3) It is difficult to do parameter studies with the complete 2-D numerical models, which take considerable computer time.

$$
-8-
$$


One observation from the numerical modeling is that once the flow field is established, it changes slowly compared to the evolution of the temperature field. As a result, we can model the area where temperature field is observed with an efficient analytical model assuming a fixed fluid flow pattern with only lateral flow. Ignoring changes in thickness through the field, the system is modeled as a single aquifer bounded above and below by regions of conductive heat transfer. Hot water is injected into the aquifer to model the heat put into the system by the intrusions. With these simplifying assumptions, analytical calculations are made of the surface gradient, temperature distribution in the cap, and temperature distribution along a flowline for all possible aquifer-cap thickness ratios and system ages. Parameter combinations which produce temperatures agreeing with observations are identified. To test the validity of the model and to arrive at an estimate of the age of the system, values of parameters consistent with the observed temperature data are compared with independent estimates from geophysical data. Of course, this model does not help us understand the, nature of the recharge of the hydrothermal system, nor does it give us an understanding of the depth or lateral extent of the intrusion zone.

QUANTITATIVE MODEL OF THE GEOTHERMAL SYSTEM Formulation

The heat transfer model is based on steady-state fluid flow with in a horizontal aquifer bounded by impermeable cap rock above and by impermeable basement below. Figure 4 shows the model configuration. The density, $p_{r}$, and specific heat, $C_{r}$, of the cap rock, aquifer rock matrix, and basement are assumed to be identical. The thermal conductivity of the cap rock and basement rock is $k_{r}$, and the density and specific heat of the reservoir fluid are $p_{f}$ and $C_{f}$, respectively. The thermal diffusivity $a_{r}=k_{r} /\left(p_{r} C_{r}\right)$. 
The reservoir porosity is $\phi$. The dominant heat transfer mechanism in layers I and III is vertical conduction and horizontal conduction is ignored. In layer II, the dominant mechanism is postulated to be horizontal fluid convection. The temperature in layer II is assumed to be independent of depth, perhaps homogenized by small scale convection cells (Younker and others, 1982). The initial temperature of the total system is zero, and the surface temperature at $z=0$ is maintained at zero. Starting at $t=0$, hot fluid flows into the aquifer through one boundary, called the input boundary of the model. The fluid velocity field $\vec{v}(x, y)$ is not determined from the equations. Instead, it is assumed to be fixed by factors outside this formulation of the problem. The fluid is incompressible, and $\vec{V}(x, y)$ is assumed stationary, with no vertical component. With these definitions and constraints, the governing field equations for layers I, II, and III are given by:

$$
\begin{aligned}
& \text { 1. } \frac{1}{a_{r}} \frac{\partial T_{I}}{\partial t}=\frac{\partial^{2} T_{I}}{\partial z^{2}} \\
& \text { II. }\left[\rho_{r} C_{r}(1-\phi)+\rho_{f} C_{f} \phi\right] h \frac{\partial T_{I I}}{\partial t}+\rho_{f} C_{f} \phi h v \cdot \nabla_{2} T_{I I} \\
& =k_{r}\left(\left.\frac{\partial T_{I I I}}{\partial z}\right|_{z=z_{0}+h}-\left.\frac{\partial T_{I}}{\partial z}\right|_{z=z_{0}}\right) \\
& \text { III. } \frac{1}{a_{r}} \frac{\partial T_{I I I}}{\partial t}=\frac{\partial^{2} T_{I I I}}{\partial z^{2}} \\
& T_{I}=T_{I I}=T_{I I I}=0, t \leq 0
\end{aligned}
$$

The horizontal gradient operator is defined by $\nabla_{2}=\hat{x} \partial_{x}+\hat{y} \partial_{y^{*}}$

It is instructive to solve Eqs. (1) to (3) for the very simple case where fluid velocity is uniform, $\vec{v}=v \vec{x}$, and the bounding layers are thermal insulators. Then Eq. (2) has the form

$$
\frac{\partial T}{\partial t}+b \cdot v \frac{\partial T}{\partial x}=0
$$


where

$$
b=\frac{\rho_{f} C_{f} \phi}{\left[\rho_{r} C_{r}(1-\phi)+\rho_{f} C_{f} \Phi\right]}
$$

The parameter $b$ is the ratio of heat stored in the pore fluid to heat stored in the saturated rock of the aquifer: Solutions consist of any function of the form $T(x, t)=T(x-b v t)$. A thermal disturbance moves undistorted through the aquifer at a velocity which is reduced from fluid velocity by the ratio b. If the input temperature is constant, then the solution consists of two regions, one fully heated to the injection temperature and the other still at the initial temperature. Consequently, to the extent that dispersion and horizontal conduction can be ignored, the lateral flow mechanism could produce a narrow transition zone such as observed at the Salton Sea. To determine how this abrupt front is modified by a conducting cap and base, the coupled Eqs. (1) to (3) must be solved.

The above field equations are cast within the framework of Eulerian continuum mechanics which requires the spatial distribution of fluid velocity to be known. Ultimately, such a distribution either must be calculated based on additional information or, lacking sufficient information, must be assumed to be of a given form. An alternate approach to the solution of the field equations is to recast them in terms of a Lagrangian perspective in which an element of fluid is followed along a streamline.

The horizontal spatial variables are replaced by a new time variable $t_{p}$, the fluid residence time. The depth $z$, and the time $t$ since the problem started, remain in the equations. Two steps are needed. First, replace $X$ and $y$ by the variables $\Sigma$ and $\eta$, where $\Sigma$ is the distance along a streamline (measured from the input side of the model) and $n$ determines which 
streamline. The term $\vec{v} \cdot \nabla_{2}$ is simplified to $v(\Sigma, n) \frac{\partial}{\partial \Sigma}$. Second, recognize that the velocity along the streamline is given by $v(\Sigma, \eta)=\left.\frac{\partial \Sigma}{\partial t_{p}}\right|_{\Sigma, n}$ where $t_{p}(\Sigma, n)$ is the time since the fluid particle at $\Sigma, n$ entered the input boundary $\left(t_{p}(0, n)=0\right)$. Thus, the second term in Eq. 2 takes on the form

$$
v \cdot \nabla_{2} T_{I I}=v(\Sigma, n) \frac{2 T_{I I}}{\partial L}=\frac{\partial \Sigma}{\partial t_{p}} \frac{2 T_{I I}}{\partial L}=\frac{2 T_{I I}}{\partial t_{p}}
$$

and the solution does not depend on the choice of streamline $(n)$. In this coordinate system, the solutions depend only on $t$ and $t_{p}$. For a given time, $t$, since flow began, the temperature $T(x, y, z)$ depends only on how long the fluid at $x$ and $y$ has been in the system, and not on the details of its path to that point. Using this coordinate system, the scaled field equations are

$$
\begin{aligned}
& \text { I. } \frac{\partial T_{I}}{\partial t^{\prime}}=p \frac{\partial^{2} T_{I}}{\partial z_{I}^{\prime 2}} \\
& \text { II. } \frac{\partial T_{I I}}{\partial t^{\prime}}+\frac{\partial T_{I I}}{\partial t_{p}^{\prime}}=\frac{\partial T_{I}}{\partial z_{I}^{\prime}} I_{z_{I}^{\prime}}=0+\frac{\partial T_{I I I}}{\partial z_{I I I}^{\prime} z_{I I I}^{\prime}}=0 \\
& \text { III. } \frac{\partial T_{I I I}}{\partial t^{\prime}}=p \frac{\partial^{2} T_{I I I}}{\partial z^{\prime}{ }_{I I I}^{2}}
\end{aligned}
$$

where

$$
\begin{aligned}
t^{\prime} & =n_{t} t \\
t_{p}^{\prime} & =n_{p} t_{p} \\
z_{I}^{\prime} & =1-n_{z} z \\
z_{\text {III }}^{\prime} & =n_{z}(z-h)-1
\end{aligned}
$$


The scaling constants are given by:

$$
\begin{aligned}
& n_{t}=\frac{k_{r}}{\hbar z_{0}\left[\rho_{0} C_{r}(T-\phi)+\rho C_{f} \phi\right]} \\
& \eta_{p}=\frac{k_{r}}{h z_{0} \rho_{f} C_{f} \phi} \\
& \eta_{z}=z_{0}^{-1} \\
& p=\frac{h}{z_{0}}\left[(1-\phi)+\frac{\rho_{f} C_{f} \phi}{\rho_{r} C_{r}}\right]
\end{aligned}
$$

The ratio $n_{t} / n_{p}$ is $b$, the ratio of the velocity of the fluid front to the velocity of the thermal disturbance. The parameter $P$ is the ratio of the heat capacity-thickness products of the saturated aquifer and cap rock.

It is clear from the above that, for a given time $t$ ' and fluid residence time $t_{p}{ }^{\prime}$, the shape of the temperature-depth distribution for the three layers depends only upon the single parameter $p$ and on the $h$ istory of the temperature $T_{j}$ of input fluid. If that injection temperature is constant, an expression for the temperature field with in the cap rock can be obtained by taking the Laplace transform of Eqs. (4)-(6) and solving the resulting set of equations subject to the appropriate initial and boundary conditions.

Continuity of temperature across the interfaces separating regions I-II and II-III is, of course, required. The solution is:

$$
\begin{aligned}
T_{I}\left(t^{\prime}, t_{p}^{\prime}, z_{I}^{\prime}\right) / T_{i} & =\mathcal{L}_{s}-1\left\{\frac{e^{-k(s, p) \sqrt{s / p} t_{p}^{\prime}} \sinh \left[\left(1-z_{I}^{\prime}\right) / s / p\right]}{s \cdot \sinh (\gamma s / p)}\right\}, \because i>0 \\
& =0, \tau \leq 0
\end{aligned}
$$

where

$$
K(s, p)=1+\operatorname{coth}(\sqrt{s / p})
$$


Here, $s$ is the transform variable corresponding to $\tau=t^{\prime}-t_{p}$ ' and $\mathcal{C}-1$ indicates an inverse Laplace transformation with respect to $s$. The temperature field $T_{I}$ in the cap rock is approximated by inverting Eq (7) numerically using a scheme proposed by Stehfest (1969).

The formulation of the temperature field to this point allows for an arbitrary flow configuration. As a result, the solution has been obtained in terms of fluid residence time with in the reservoir, without having any knowledge of the position of any fluid element at time $t$ ' and residence $t$ ime $t_{p}$ '. Having no knowledge of the actual flow field, one must assume a flow geometry to determine the location of the fluid element. In the dimensionless form, the fluid residence times for radial and linear flow can be determined from conservation of mass assuming incompressible fluid flow:

$$
\begin{aligned}
& t_{p}^{\prime}=\frac{k_{r} o^{\pi}}{C_{f} Q_{r}} r^{2} \quad \text { (radial) } \\
& t_{p}^{\prime}=\frac{r}{C_{f}{ }^{2}} x^{\prime} \quad \text { (linear) }
\end{aligned}
$$

where $Q_{r}$ (mass/time) and $Q_{\ell}$ (mass/length.time) are the injected mass flow rates for radial and linear flow, respectively. The dimensionless numbers $r^{\prime}=r / z_{0}$ and $x^{\prime}=x / z_{0}$ are the scaled distances from the injection boundary.

This formulation is similar to one developed by Ardonin (1964), and applied to geothermal injection calculations more recently by a variety of workers. The main distinctions between the approaches concern assumptions about horizontal conduction in the aquifer, allowable flow geometric in the aquifer, and thickness of the cap and basement. Our formulation does not include horizontal conduction in the aquifer in contrast to the Avdonin approach. Avdonin immediately assures radial flow in the aquifer, while our 
fluid residence time approach is somewhat more general. We assume a given surface temperature, which for long time periods insures that the temperature field in the cap rock will not be an image of the temperature field in the basement. Avdonin's formulation, on the other hand, assumes an infinitely thick cap and basement.

\section{General Features of the Mode 1}

The applicability of this model can be illustrated by comparing model calculations with observations of the major characteristics of the thermal anomaly. Two samples of calculated temperature fields for horizontal, radial, incompressible fluid flow are shown in Fig. 5. The particular parameters for this problem are listed in Table 1. Several properties of the observed temperature field are seen in the model. Figure 5A shows the calculated vertical temperature profiles in the cap (layer I) at various distances from the fluid source after 9340 years. As observed in Zone $A$, the calculated gradient is nearly constant with depth and varies little with location for .' distances of 0 to $2.5 \mathrm{~km}$ from the source. As observed in Zone $C$, the near-surface gradient decreases over a short distance and the gradients increase noticeably with depths for distances between 2500 and $3000 \mathrm{~m}$ from the source. Finally, as observed in Zone B, calculated temperature profiles beyond $3 \mathrm{~km}$ are not yet perturbed by the hydrothermal system.

The evolution of the gradient distribution at the surface is illustrated in Fig. 5B. The near-surface gradient is strongly influenced by the insulating nature of the cap. During early times, before steady-state heat flow can be developed anywhere in the cap, the heat from the aquifer is not fully detectable at the surface. At later times, the gradient gradually decreases with distance from the source when the heat loss through the cap balances the heat delivered to the aquifer by the fluid. However, in a fairly 
narrow $r$ ange of intermediate times (in this case, 6,000 - 20,000 years) the gradient does not change much with distance near the center but drops off rapidly past some critical distance.

From this example, it is seen that for a restricted range of ages, results from a simple model match some of the features of the temperature distribution in the Salton Sea Geothermal Field. In the following section, we determine the model parameters that produce the best fit to the observed temperature data.

APPLICATION OF THE MODEL

Age and Flow Rate Estimates

The simplicity of the above model makes it possible to determine the entire range of parameters that provide solutions which match the thermal data from the field. Thus, we can identify a range of flow rates and system ages consistent with thermal data and other geophysical measurements in the field.

The gradient data from Fig. 2 were edited and put into a one-dimensional : plot which can be compared to curves such as those in Fig. 5B. Lee and Cohen (1979) recognize that at least four of their shallow well gradients are so large and so different from the deep well values that they must be superficial phenomena caused by local hydrologic circulation. Because our model does not attempt to explain variations on this scale, we eliminated these data. A regional gradient of $0.11^{\circ} \mathrm{C} / \mathrm{m}$ was subtracted from the data. Because of the roughly semicircular shape of the on-shore thermal anomaly, we assumed a radial geometry for flow in the model. An arbitrary center near the middle of the magnetic anomaly was chosen, and the existing surface temperature-gradient data were plotted versus distance from this center (Fig. 6). Two features are prominent on the plot. First, the two zones (A and B) referred to earlier can be recognized. They are separated by a narrow transition zone 4 to $5 \mathrm{~km}$ from 
the center. Second, a slight $r$ ise in gradient with distance in Zone $A$ is observed. This second feature cannot be matched by the simple ilow model in beds of uniform thickness.

Once radial flow is assumed, the shape of the temperature-distance curves depends only upon two parameters. One parameter, $p$, is simply the ratio of the heat capacity-thickness product of the aquifer to that of the cap rock. The other parameter is $t '$, the system age since flow started. The scale factor for calculating distance from $t_{p}$ ' must also be estimated. These parameters can not be directly determined from the measured thermal data. A procedure was developed to objectively relate the calculated thermal field to observations. For a given geometry, distance from the heat source can be related to $t_{p}$ ' by $E q .(8)$ or (9). The scale factor in this relationship is estimated from the following procedure. The solution for temperature (Eq. 7) is identically zero if $t^{\prime}-t_{p}^{\prime}<0$. Consequentiy, at each time, $t^{\prime}$, there is a distance $r_{b}$ beyond which the initial temperature field is undisturbed. If $p$ and $t$ ' are chosen, this parameter can be estimated from the. thermal data, and is used to represent the scaling from $t_{p}$ ' to distance, such that $r=r_{b} \sqrt{t_{p} / t}$. Therefore, given a value of $r_{b}$, the temperature field within the cap can be calculated for any $p$ and $t$ ', using Eq. (7).

The thermal breakthrough distance $r_{b}$ represents the thermal front in the aquifer. Because of the thermal inertia of the cap, $r_{b}$ cannot be determined visually from the surface gradient data in Fig. 6. An average cap thickness $z_{0}$ of $500 \mathrm{~m}$ (based on the thermal data, Younker and others, 1982) was chosen. For each $p$ and $t^{\prime}$, the optimal value of $r_{b}$ was found. The criterion used was the sample variance or average squared difference between the field data and the calculated gradients. Contour plots of the optimal 
thermal breakthrough distance and the resulting variances as a function of $p$ and $t$ ' are shown in Figs. 7 and 8.

A trough of low variance extends from the middle of the plot to the lower right. Models characterized either by high values of $t$ ' or by low values of $p$ and $t$ ' do not fit the data as well as do models with parameters with in this trough. This is illustrated by a comparison of four models with different parameter combinations represented by the cases $A, B, C$, and $D$ in Figure 8 . Figure 9 is a plot of the surface gradient versus the distance for these four models characterized by different values of $t$ ' and $p$. The gradient data have been normalized so the value at the center of the field is 1 and the value at infinity is 0 . Models which match the data well are characterized by a broad flat zone of high gradient in the center and by a narrow transition zone to the zone of low gradient (Model D). The other models generally have a more gradual transition from the zone of high gradient to the zone of low gradient.

Using only the shape of the plot of surface temperature gradient versus distance, it is possible, therefore, to identify preferred values of $t$ ' and $;$ ' p. This space can be further constrained by imposing the aquifer geometry inferred from geophysical data. From equation 6, $\mathrm{p}$ is approximately $\mathrm{h} / \mathrm{z}_{\mathrm{o}}$. The cap thickness is chosen to be $500 \mathrm{~m}$, based on the interpretation of the temperature gradient data in deep wells (Younker and others 1982). The maximum thickness of the aquifer can be constrained by the depth to basement inferred by Frith (1978) from seismic refraction studies and is somewhere between 1500 and $4500 \mathrm{~m}$. Alternative constraints on the aquifer thickness may be provided by the resistivity and magnetic data. Kasameyer (1976), using the surface resistivity measurements, mapped two resistive zones inferred to be the top and bottom of the hydrothermal system. In the main part of the field, the top of the shallow resistive zone is estimated to be shallower than $500 \mathrm{~m}$, a depth generally consistent with other estimates of the cap thickness. The 
top of the lower resistive zone is estimated to be shallower than 2000, making the aquifer $1500 \mathrm{~m}$ thick. A slightly thicker aquifer might be inferred from the magnetic data. Griscom and Muffler (1971) estimate a dike-plutonic complex at approximately $2500 \mathrm{~m}$ on the basis of the large magnetic anomaly that runs the length of the area. Uniess this material is extensively fractured, this depth probably represents a maximum depth of reservoir rock.

These estimates allow the parameter $p$ to be constrained to values between 3 and 9. Low model variances are consistent with this constraint, indicating that the model is plausible.

The model can be used to draw conclusions about the geothermal system, such as estimates of its age and rate of fluid influx into the modeled area. In order to do this, values of the heat capacity of the fluid, and heat capacity, thermal conductivity and density of the rock must be chosen. We used the values in Table 1, which were believed to be reasonable for the sedimentary rocks at the SSGF. Errors resulting from uncertainties in the cap and aquifer thicknesses, and in the best parameter fit are believed to be much larger than the errors resulting from uncertainties in these physical properties.

The model can be used to calculate rates of fluid flow with in the hydrothermal system. A dimensionless flow parameter can be defined as:

$$
\zeta=\log \frac{Q_{r} C_{f}}{k_{r} z_{0}}=\log \frac{\pi r_{b}{ }^{2}}{t^{\prime} z_{0}{ }^{2}}
$$

Where we have used Eq. (8) and the fact that, at thermal breakthrough, $r=r_{b}$ and $t^{\prime}=t_{p}^{\prime}$. Figure 10 , is a contour plot of $\zeta$ calculated from the optimal $r_{b}$ values in Fig. 7 . In the preferred portion of the plot, convective flow varies from $1 \times 10^{7} \mathrm{~m}^{3} /$ year to $3 \times 10^{7} \mathrm{~m}^{3} /$ year. 
It is possible to use the flow model to estimate the system age. In Figure 11, values of system age, $t$, are contoured from $t^{\prime}=\left[k_{r} /\left(\rho_{r} c_{r} p z_{0}^{2}\right)\right] t$. Estimates of system age for this model range from 3,000 to 20,000 years. As a comparison and using the potassium-argon method Muffler and White 1969, the surface volcanic rocks have been dated at 16,000 years with an upper bound of 56,000 years. Randall (1974) argues that these data result in a reasonable estimate for the age of the latest geothermal system in the area. Dutcher and others (1972) estimate the age of the steady-state flow system to be "not longer than 50,000 years but probabiy more than 25,000 years." Their estimate is based on the brine composition and on an assumed mechanism for the accumulation of dissolved minerals in the brines. While our system age estimates are somewhat lower than those previous estimates, it is agreed that the Salton Sea System is a very young sys tem.

\section{Comments on Assumptions in Mode 1}

He have assumed that horizontal conduction can be ignored in this model. The assumption that horizontal conduction is much smaller than vertical conduction in layers $I$ and III is valid if $T=2 k_{r} /\left(C_{f} q\right)$ is less than $I$ (Hanson, 1977). The assumption that horizontal conduction is smaller than horizontal convection in the aquifer is valid if $c_{f} q / k_{f}=2 k_{r} / k_{f} T$ is larger than 1. In both of these tests, $q$ is the fluid mass flux-aquifer thickness product. Because the rock conductivity is generally larger than the fluid conductivity, the first test is more restrictive than the second. For radial flow, $q=Q_{r} / 2 \pi r$. From equation 8 ,

$$
\frac{4 r z_{0}}{r_{b}^{2}}=\frac{4 \pi k_{r} r}{C_{f}{ }^{Q_{r}}}=T
$$


For the entire range shown in Fig. 7. $.0012<t / r_{b}^{2}<.027$.

For the first assumption to be valid

$$
r<\min \left[\frac{1}{4 z_{0}}\left(\frac{r_{b}^{2}}{t^{\top}}\right)\right]=18.5 \mathrm{~km}
$$

Therefore, these assumptions are justified because we apply the model to an area less than $10 \mathrm{~km}$ across.

The upper bound on the age is determined primarily from the width of the transition zone, which indicates the volume of hot material is expanding laterally fast enough so that the cap cannot stay in equilibrium with it. The age is essentially estimated by determining the present flow rate from that zone and by assuming the flow rate has been constant since the system started. The age would be different if the system had pulses of fluid flow or if it resulted from a single intrusion, with the fiow rate decaying as the intrusion cools. If the system flow rate is decaying monotonically with time, the actual age will be shorter than estimated. It is much more difficult to . limit the age of a puilsed system, but a heuristic argument can be made. If the fluid flow were to temporarily stop, (a circumstance which may not be possible physically), thermal conduction would broaden the transition zone, and the temperature in the aquifer would tend to vary slowly from the center to the edge of the system. Then, a future "pulse" of flow would push this smoothed thermal front outwards but would not steepen it. Consequently, the transition zone will reflect the smooth character of the earlier pulse, unless the pulses are separated by enough time to allow nearly complete cooling of the system between pulses. Consequently, it is suggested that the present thermal field is the result of a near.7y, continuous pulse of 3,000 to 20,000 years duration, that it was preceded by a period of little flow, and that information about previous "pulses" is not contained in the thermal field. 
One feature of the temper ature data is not matched by our model. The observed temperature at the base of the cap (see Younker, and others, 1982) decreases more smoothly with distance than the calculated temperatures in the aquifer. This conflict probably is caused by the assumption that the thermal cap has uniform thickness throughout the field.

Comparison with Other Models of Geothermal Systems

There have been several recent attempts to develop mathematical models of the fluid and heat transfer in specific geothermal systems. Garg and Kassoy (1981) and Donaldson (1982) have recently provided detailed reviews of these studies. Most of the models constructed for thermal-hydrological systems in the Salton Trough are conceptually similar to the model presented here for the Salton Sea System. Upwelling hot fluids are laterally diverted by an impermeable cap rock or low vertical permeability reservoir rock resulting in a significant horizontal component of fluid flow in the upper portions of the field.

The model of the East Mesa field in the Imperial Valley, California, presented by Kassoy and Goyal (1979) and Goyal and Kassoy (1980) is, for example, qualitatively and quantitatively similar to the model developed here for the Salton Sea field. They postulate fault zone changing of a shallow geothermal reservoir, with hot fluid assumed to flow horizontally as the result of low vertical permeability. They model only a limited part of the complete circulation pattern, and evaluate the effect of a variety of parameters such as mass flow rate, Rayleigh number and fault width on pressures, velocities and temperatures throughout the aquifer. By including the details of the upflow in the fault zone they have developed a more complicated mathematical description of the field than the one presented here. In contrast, our simpler formulation enables us to rigorously compare 
model calculations for a smaller number of parameters to the observed temperature distribution in the cap rock.

Riney and others, 1977, have developed a preproduction areal model of the Salton Sea upper reservoir which also postulates significant horizontal flow. Their. two-dimensional numerical simulation of horizontal flow with in the upper reservoir, however, shows flow directions uniformly from southeast to northwest across the area modeled in this paper. Thus, they model the flow of cold water into the system in exactly the opposite direction to the flow of hot water postulated in our model.

In order to analyze this contradiction, it is necessary to understand the uncertainties associated with determining natural flow directions and rates in geothermal systems. Ideally, one could use tracer studies or direct pressure measurements to infer the flow directions. To our knowledge, there have been no definitive tracer tests designed to evaluate the natural flow, and the present relatively ambiguous pressure data indicates no significant lateral pressure gradients.

In the absence of this type of data, two types of approaches can be used to infer the natural flow directions. First, one can use field observations as a basis for estimating pressure variations, and use these estimates to calculate flow directions and rates. This is the approach taken by $R$ iney and others, (1977), in which they use thermal data from the ends of the field, the dip of the reservoir rocks and the brine equation of state to calculate a pressure drive across the field. Alternatively, one could infer flow directions from an analysis of field characteristics without first estimating the pressure variation. The procedure is this case is to constrain flow directions by analyzing observed products of that flow. Elders and others (1983), recently used this type of approach to constrain natural flow patterns 
in the Cerro Prieto field. They used mineralogic and isotopic data from well cuttings and cores to infer the flow directions.

In this paper, we have similarly applied this approach, using geophysical data rather than geochemical data to infer the characteristics of the natural flow. Flow directions are postulated using the observed pattern of geophysical anomalies, and the inferred characteristics of the reservoir rock. Applicability of the model is assessed by comparing model calculations with the observed thermal gradient data. Because the two different approaches yield radicaliy different results for the Salton Sea field, it is necessary to analyze their implications in more detail.

A horizontal pressure gradient away from the center of the field is required to produce the fluid flow patterns used in our model. The pressure difference at two distances can be calculated for the radial flow mode by integrating Darcy.'s Law.

For the largest estimated flow rate $\left(Q_{r}=3 \times 10^{7} \mathrm{~m}^{3} /\right.$ year $)$, viscosity for hot brine ( 0.1 centipoise), moderate permeability, (100 MD), and an aquifer thickness of $2000 \mathrm{M}$, then

$$
P\left(r_{1}\right)-P\left(r_{2}\right)=(11 \text { psi }) \log \frac{r_{2}}{r_{1}} \text {. }
$$

For example, measurements at opposite ends of the field (perhaps at $r=1 \mathrm{~km}$ and $r=5$ ), a pressure difference of up to 13 psi could be expected. Measurements would have to determine formation pressures within a single hydrologic unit, and corrected accurately for dip of the unit between the wells. If correction terms can be calculated accurately to a few psi, then the predicted pressure gradient could be detected.

Less accurate pressure measurements could be used to distinguish between the model discussed here and the Riney, et al model. That model is based on similar thermal data, but predicts a pressure drop of over. 50 psi driving cold 
- fluid into the geothermal field. This pressure drive comes from estimating the pressure at either end of the field.

These pressures are calculated from the observed temperature - depth profiles, apparently assuming:

a) The upper reservoir is a water-table aquifer, with the water-table at the ground surface (Morse and Stone (1979) concluded the upper reservoir is a confined aquifer.).

b) Density can be calculated assuming salinity is fixed (Helgeson . (1968) observed that salinity varies with temperature in this field, keeping density nearly constant).

c) There is no vertical convection in the upper reservoir. In order to maintain high temperatures in the reservoir given the influx of cold water from the southeast, their model requires a significant input of hot fluid from the lower reservoir, in conflict with conclusions drawn from oxygen isotope studies (Kendall, 1976), observed vertical salinity differences, and inferred vertical permeability.

An error of only $4 \%$ in the larger of the two calculated pressures would be adequate to account for the 50 psi pressure drive which they calculated. We believe that the uncertainties resulting from the above assumptions are large enough that flow in the opposite direction is possible.

Furthermore their model does not attempt to account for the natural evolution of the system, or to fit other aspects of the thermal field, like the uniform heat flow with in the thermal cap. Consequently, we do not believe that the ir preproduction model invalidates ours.

Future Investigations of the Hydrothermal System

Hydrothermal models of the type presented in this paper are useful for several reasons. First, they permit estimation of parameters that are not 
easily or directly measurable in the field, as in the case of the age of the system and flow rates. Second, they provide a basis for extrapolating the data beyond the drilled or surveyed area. These extrapolations have led to refined estimates of the recoverable thermal energy (Younker and Kasameyer, 1978). In this application the model highlights the resource potential of the transition region where low surface gradients are found above a hot aquifer. Third, they delineate areas of major uncertainty and, therefore, can guide future efforts toward increased understanding of the subsurface processes. There is extensive data from one part of the hydrothermal system in the Salton Sea area. Within the surveyed field, horizontal flow in a confined aquifer away from a largely unspecified heat source adequately explains some characteristics of the thermal anomaly. Major aspects of the hydrothermal system remain subject to question. The following questions remain regarding the aquifer: 1) How deep is the region of horizontal flow? 2) What is the plan view of the flow to the north of the field? and 3 ) What are the recharge pathways? The following questions remain regarding the heat source: 1) What: are the exact locations of intrusfons? 2) How far apart are they? 3) How hot are they? 4) What is the rate of intrusion?

The simple hydrothermal model presented in this paper provides a framework for investigating some of these questions. The model generates testable predictions which can be evaluated both by surface heat-flow measurements and by observations in additional deep wells. The model predicts that if the host rocks were uniformly permeable then:

1) An area of high heat flow (4 to 5 times normal) and of uniform heat flow will be found to the northwest of the volcanic buttes.

2) The area of uniform heat flow will be bounded by a narrow $(1 \mathrm{~km}$ wide) zone of rapid transition to regional heat flow. 
Lee and Cohen (1979) attempted to measure heat flow beneath the Salton Sea, northwest of the volcanic buttes, using a $2-m$ lance-like thermal probe. They detected a thermal anomaly of areal extent similar to the SSGF, but question the validity of these measurements because offshore heat flow values are a factor of three above values measured on-shore. The predicted anomalies could be detected and delineated by heat-flow measurements in relatively shallow holes. Furthermore, in the transition region, the model predicts that, as the hydrothermal zone is approached, the cap-temperature gradient should increase with depth. This prediction can be tested by deeper wells at the margin of the zone of high heat flow.

If the model is supported by new data and the location of the transition region is mapped by the shallow heat-flow measurements, then quantitative estimates can be made of the location, volume, and rate of input of the heat source. As an example, assume that a radial flow model is supported by the spatial geometry of the boundary region. Using the simple expressions for heat input to the system, it is possible to calculate the total heat input to : the system per unit thickness of aquifer in the preproduction state. Therefore, assuming basaltic intrusion, one can calculate the volume of magma required to intrude and lose its heat to each $k$ ilometer of aquifer. If this can be constrained further by direct or indirect measurement of the aquifer thickness, estimates of the intruded magma volume can be made. These estimates could guide any future efforts to explore the deeper portions of the hydrothermal system.

SUMMARY AND CONCLUSIONS

The tectonic setting and geophysical data suggest a zone of localized intrusion in the offset region between the Brawley fault and the San Andreas fault. Mafic and silicic dikes intrude to with in one kilometer of the surface 
- in this area, and may be the product of the magmatic body which provides the source of heat for the Salton Sea Geothermal Field. Because of low vertical permeability, convection cells which have large scale vertical motion with in the explored area are precluded. High horizontal permeability and demonstrated lateral continuity of reservoir sands promote lateral flow of fluid away from the zone of intrusion.

Two features of the temperature field put additional constraints on this conceptual mode1. First, uniform steady-state heat flow is observed in a $500-m$ thick thermal cap over an area of 30 to $40 \mathrm{~km}^{2}$. This observation indicates that the fluid flow patterns and rate of heat delivery to the thermal cap in this area have not changed for a substantial period of time. Second, the periphery of the high heat-flow zone is abrupt and the thermal gradient in the cap increases significantly with depth as the hydrothermal zone is approached. These observations indicate that heat has been delivered to the periphery for a much shorter time than is required for conduction in the cap to come to steady-state equilibrium and that the region of high temperature below the cap is expanding.

A two-dimensional model of horizontal fluid flow outward from a localized heat source produces thermal fields which match these observations. The model is simple enough that analytical results can be evaluated for a broad range of parameters. The system age is estimated by minimizing the variance between the observed surface heat-flow data and the model. Age estimates range from 3000 to 20,000 years, consistent with the hypothesis that the Salton Sea Geothermal field is part of a very young hydrothermal system. 
Professor Wilfred Elders of University of California at Riverside provided extensive comments which were incorporated into this manuscript. The manuscript was improved as a result of reviews by James Mercer, Al Duba and $J$ im Hannon. We acknowledge support of the Office of Basic Energy Sciences and the Division of Geothermal Energy of the Department of Energy. 
Avdonin, N. A., 1964, Some formulas for calculating the temperature field of a stratum subject to thermal injection: Izv. Vysshikh Uchebn. Zavedence, Nefti Gaz 7, no. 3, p. 37-41.

Biehler, S., and Combs, J., 1972, Correlation of gravity and geothermal anomalies in the Imperial Valley, southern California: Geological Society of America Abstracts with Prograns, v. 4, No. 3, p. 128. Bird, D. K., and Elders, W. A., 1975, Hydrothermal alteration and mass transfer in the discharge portion of the Dunes geothermal system, Imperial Valley of California, U.S.A.: 2nd U.N. Symposium on the Development and Use of Geothermai Resources, San Francisco, p. 285-296.

Bird, D. K., and Norton, D. L., 1981, Theoretical prediction of phase relations among Salton Sea geothermal system brines: Geochimica et Cosmochimica Acta, V. 45 , p. $1479-1493$.

Black, H. T., 1975, A subsurface study of the Mesa geothermal anomaly, Imperial Valley, California: University of Colorado, Boulder, Colorado, Publication No. CUMER 75-5.

Donaldson, I. G., 1982, Heat and mass circulation in geothermal systems:

Annual Review Earth Planetary Science, V. 10, p. 377-395.

Dutcher, L. C., Hardt, W. F., and Moyle, W. R., Jr., 1972, Preliminary appraisal of ground water in storage with reference to geothermal resources in the Imperial Valley area, California: United States Geological Survey Circular 649, 57p.

Elders, W. A., and Biehler, S., 1975, Gulf of California rift system and its implication for the tectonics of western North America: Geology, v. 3. No. 2 , p. 85-87. 
Elders, W...A., Williams, A. E., and Schiffman, P., 1983, Hydrothermal flow regime and magmatic heat source of the Cerro Prieto Geothermal System, Baja California, Mexico: Geothermics, V. 13, p.

Elders, W. A., Rex, R. W., Meidav, T., Robinson, P. T., and Biehler, S., 1972, Crustal spreading in southern California: Science, v. 178, p. 15-24. Elders, W.A., Hoagland, J.R., and Williams, A. E., 1980, Hydrothermal

alteration as an indicator of temperature and flow regime in the Cerro Prieto geothermal field of Baja California: Geothermal Resources Council, Transactions, v. 4, p. 121-124.

Frith, R. B., 1978, A seismic refraction investigation of the Salton Sea Geothermal area, Imperial Valley, California [M.S. thesis]: University of California, Riverside, California, 94 p. (unpublished).

Garg, S. K. and Kassoy, D. R., 1981, Convective heat and mass transfer in hydrothermal systems: In Geothermal systems: Principles and Case Histories, ed. L. Rybach, L. J. P. Muffler, P. 37-76. Gilpin, B., and Lee, Tien-Chang, 1978, A microearthquake study in the Salton : Sea geothermal area, California: Bulletin of the Seismological Society of America, v. 68, p. 441-450.

Goyal, K. P. and Kassoy, D. R., 1980, Fault-zone controlled charges of a liquid dominated geothermal reservoir: Journal of Geophysical Research, V. 85 , p. $1867-75$.

Griscom, A., and Muffler, L. J. P., 1971, Aeromagnetic map and interpretation of the Salton Sea geothermal area, California: United States Geological Survey, Geophysical Investigation, Map GP 754.

Hanson, J. M., 1977, Heat transfer effects in forced geoheat recovery systems, [Ph.D. thesis]: Oregon State University, Corvalis, Oregon, p. 168-175. 
Helgeson, H. C., 1968, Geologic and thermodymamic character istics of the

Salton Sea geothermal system: American Journal of Science, V. 266, p. 129-166.

Hi11, D., 1977, A model for earthquake swarms: Journal of Geophysical Research, v. 82, p. 1347-1351.

Hill, D., Mowinckel, P., and Peake, L., 1975, Earthquakes, active faults and geothermal areas in the Imperial Valley, California: Science, v. 188, p. 1306-1308.

Howard, J. H., 1976, Comparison of the structure of a part of the San Jacinto fault system with the Salton Sea Geothermal Field vicinity: Geological Society of America Abstracts with Programs, v; 8, p. 929.

Johnson, C., and Hadley, D., 1976, Tectonic implications of the Brawley earthquake swarm Imperial Valley, California, January 1975: Bulletin Seismological Society of America, v. 66, p. 1133-1144.

Kasameyer, P. W., Younker, L. W., and Hanson, J., 1983, Inversion approach for thermal data from a convecting hydrothermal system: Lawrence Livermore ; National Laboratory, Livermore, California, Publication No. UCRL-88882, Proceedings IUGG 1983 Inter-disciplinary Symposium No. 10 "Heat Flow and Geothermal Processes," Journal of. Geodynamics, in press.

Kasameyer, P. W., 1976, Preliminary interpretation of resistivity and seismic refraction data from the Salton Sea Geothermal Field: Lawrence Livermore National Laboratory, Livermore, California, Publication No. UCRL-52115. Kassoy, D. R., and Goyal, K. P., 1979, Modeling heat and mass transfer at the Mesa geothermal anomaly, Imperial Valley, California: Lawrence Berkeley Laboratory, Berkeley, California, Publication No. LBL-8784. 
Kendall, c., 1976, Petrology and stable isotope geochemistry of three wells in the Buttes area of the Salton Sea Geothermal Field, Imperial Valley, California, U.S.A. [M.S. Thesis]: University of California, Riverside, Riverside, CA, 227p.

Lachenbruch,.A., Sass, J., Monroe, R., and Moses, T., 1976, Geothermal setting and simple heat conduction models for the Long Valley Caldera: Journal Geophysical Research, v. 81, p. 769-784.

Lachenbruch, A., and Sass, J., 1978, Models of an extending lithosphere and heat flow in the Basin and Range province: Geological Society of America Memoir, v. 152, p. 209-250.

Lau, K. H., 1980, Effect of permeability on cooling of a magmatic intrusion in a geothermal reservoir: Lawrence Livermore National Laboratory, Livermore, California, Publication No. UCRL-52888, 28p.

Lee, T., and Cohen, L., 1979, Onshore and offshore measurements of temperature gradients in the Salton Sea geothermal area, California: Geophysics, V. 44, p. 206-215.

Lomnitz, C., Mooser, F., Allen, C., Brune, J. N., and Thatcher, W., 1970,

Seismicity of the Gulf of California region, Mexico--preliminary results: Geofis. Int., v. 10, p., 37.

McDowe11, S. D. and Elders, W. A., 1980, Authigenic layer silicate minerals in borehole Elmore 1, Salton Sea geothermal field, California, U.S.A.:

Contributions to Mineralogy and Petrology, V. 74, p. 293-310. McEuen, R., Mase, C., and Loomis, W., 1977, Geothermal tectonics of the Imperial Valley as deduced from earthquake occurrence data: Geothermal Resources Council Transactions, v. 1, p. 211-213. 
Morse, J. G., and Stone, R., 1979, Evaluation of reservoir properties in a portion of the Salton Sea Geothermal Field: Lawrence Livermore National Laboratory, Livermore, California, Publication No. UCRL-52756, 52p. Muffler, L. J. P., and White, D. E., 1969, Active metamorphism of upper Cenozoic sediments in the Salton. Sea Geothermal Field and the Salton Trough, southeastern California: Geological Society of America Bulletin, v. 80, p. $157-182$.

Noble, J. E., Manon, A. M., Lippmann, M. J., and Witherspoon, P. A., 1977, A Study of the structural control of fluid flow within the Cerro Prieto Geothermal Field, Baja California, Mexico: Lawrence Berkeley Laboratory, Berkeley, California, Publication No. LBL-7001. Randal1, W., 1974, An analysis of the subsurface structure and stratigraphy of the Salton Sea geothermal anomaly, Imperial Valley, California [Ph.D. thesis]: University of California, Riverside, California (unpublished). Riney, T. D., Pritchett, J. W. and Garg, S. K., 1977, Salton Sea Geothermal Reservoir Simulations: Proceedings, Third Workshop Reservoir Engineering, Stanford University, Stanford, California, p. 179-184. Riney, T. D., Pritchett, J. W., Rice, L. F., and Garg, S. K., 1979, A preliminary model of the East Mesa hydrothermal system, Proceedings of the Workshop on Geothermal Reservoir Engineering: Stanford University Geothermal Program, Stanford University, Palo Alto, California. Robinson, P. T., Elders, W. A., and Muffler, L. J. P., 1976, Quaternary Volcanism in the Salton Sea Geothermal Field, Imperial Valley, California: Geological Society of America Bulletin, v. 87, p. 347-360. Sharp, R., 1967, San Jacinto fault zone in the peninsular ranges of southern California: Geological Society of America Bulletin, v. 78, p. 705-730. Stehfest, H., 1969, Al gor ithm 368 in Collected Al gor ithms from CACM. 
Swanberg, C. A., 1975, The Mesa Geothermal Anomaly, Imperial Valley, California: A comparison and evaluation of results obtained from surface geophysics and deep drilling: 2nd U.N. Symposium on the Development and Use of Geothermal Resources, San Francisco, p. 1217-1229.

Thatcher, W., and Brune, J., 1971, Seismic study of oceanic ridge earthquake swarm in the Gulf of California: Geophysical Journal of the Royal Astronomical Society, v. 22, p. 473-489.

Younker, L., and Kasameyer, P. W., 1978, A revised estimate of recoverable thermal energy in the Salton Sea geothermal resource area: Lawrence Livermore National Laboratory, Livermore, California, Publication No. UCRL-52450, $13 \mathrm{p}$.

Younker, L., Kasameyer, P., Tewhey, J., 1982, Geological, geophysical, and thermal characteristics of the Salton Sea Geothermal Field, California: Journal of Volcanology and Geothermal Research, V. 12, p. 221-258. 
Figure 1. Location of the Salton Sea Geothermal Field (SSGF) and nearby faults in the Imperial Valley (modified from Elders and others, . 1972). The SSGF lies with the Salton Sea Known Geothermal Resource area indicated by the irregular boundary southeast of the Salton Sea. Basement rocks are indicated by stippled pattern.

Figure 2. Locations of thermal zones $A, B$ and $C$. The zones are super imposed on a map of thermal gradients $\left({ }^{\circ} \mathrm{C} / \mathrm{per} 100 \mathrm{~m}\right)$. Open symbols indicate data from deep wells (Younker and others, 1982), and closed symbols indicate data from shallow wells (Lee and Cohen, 1979).

Figure 3. Representative temperature depth profiles from Zone A wells and Zone $C$ wells. The Sinclair wells are from Zone $C$, where the gradient increases with depth. Other wells are in the central part of the field (Zone A).

Figure 4. Geometry of the flow model showing the cap rock, aquifer, and basement thickness.

Figure 5. Samples of calculated temperature fields in layer I for horizontal radial incompressible-flow: $5 A$ shows the vertical temperature profile in the cap at different distances from fluid source after 9340 years, 5B shows the evolution of the gradient distribution at the surface for different times. 
Figure 6. Observed surface temperature gradients plotted versus distance from the postulated center of the Salton Sea Geothermal Field. A regional value of $0.11^{\circ} \mathrm{C} / \mathrm{m}$ is subtracted from the gradient data.

Figure 7. Values of the thermal breakthrough distances (in $\mathrm{km}$ ) which minimize the squares of the differences between the thermal gradients from field data and from a model calculated for various values of $p$ and $t$ ' contoured on a plot of $\log t$ ' versus $\log p$.

Figure 8. Model variance (sum of squares of differences between the modeled thermal gradients and the observed) contoured on a plot of log t' versus $\log \mathbf{p}$.

Figure 9. Plots of scaled surface temperature gradient versus distance for different models. The parameter values for each case are indicated by symbols on Figure 8 . Of these cases, model $D$ fits : the observations best.

Figure 10. Dimensionless flow parameter, contoured on a plot of $\log t$ ' versus $\log$ p. Numbers in parentheses are the computed volumetric flow rates in millions of cubic meters per year, using the parameter values listed in Table 1.

Figure 11. Estimates of the system age superimposed on the model variance plot. Parameter values used in the calculation are listed in Table 1. Low variance models are associated with ages from 3,000 to 20,000 years. 
TABLE 1. Parameters used in several calculations.

$\begin{array}{ll}Q r=1.6 \times 10^{7} \mathrm{~m}^{3} / \mathrm{mr} & k_{r}=3 \mathrm{w} / \mathrm{m}-\mathrm{k} \\ \phi=0.20 & \rho_{f}=1000 \mathrm{~kg} / \mathrm{m}^{3} \\ z_{0}=500 \mathrm{~m} & C_{f}=4180 \mathrm{~J} / \mathrm{kg}-\mathrm{K} \\ C_{r}=954 \mathrm{~J} / \mathrm{kg}-\mathrm{K} & h=4270 \mathrm{~m} \\ \rho_{r}=2500 \mathrm{~kg} / \mathrm{m}^{3} & \end{array}$

Where $Q_{r}$ is the injected mass flow rate for radial flow

$\phi$ is the porosity of the aquifer

$z_{0}$ is the depth of the top of the aquifer

$C_{r}$ is the specific heat of the rock matrix

$P_{r}$ is the density of the rock matrix

$k_{r}$ is the thermal conductivity of the caprock and basement rock

$\rho_{f}$ is the density of the reservoir fluid

$C_{f}$ is the specific heat of the reservoir fluid

$h$ is the aquifer thickness. 


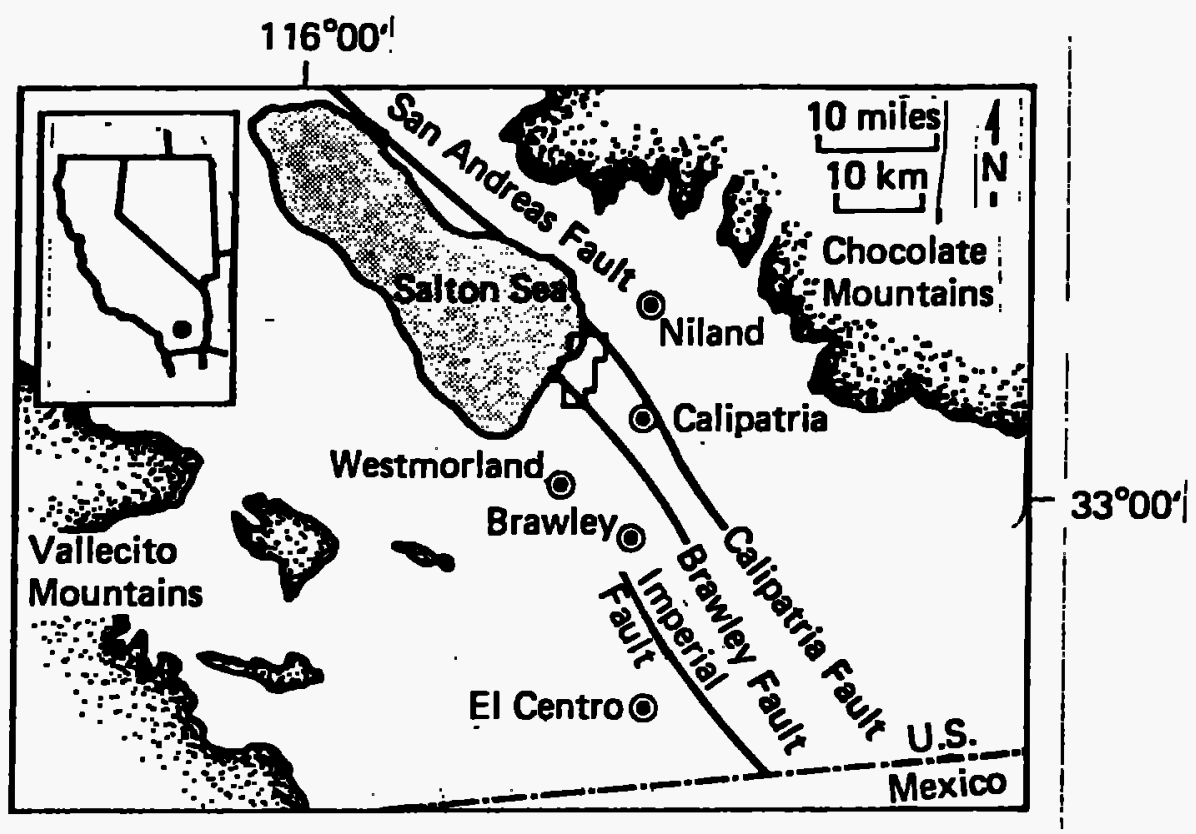

FIG. 1 - RASAMEYER 


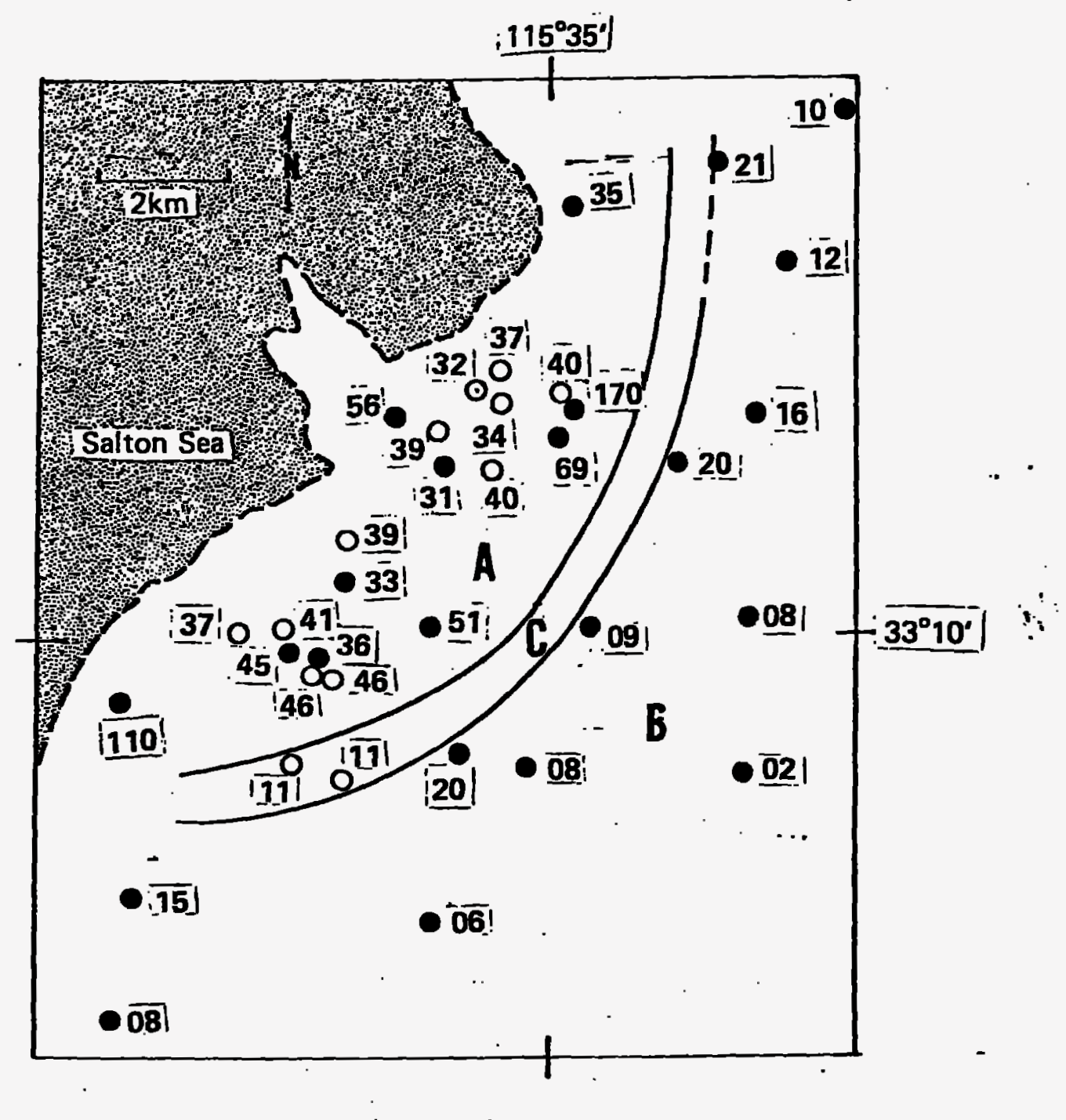

FIG. 2 - KASAMEYER 

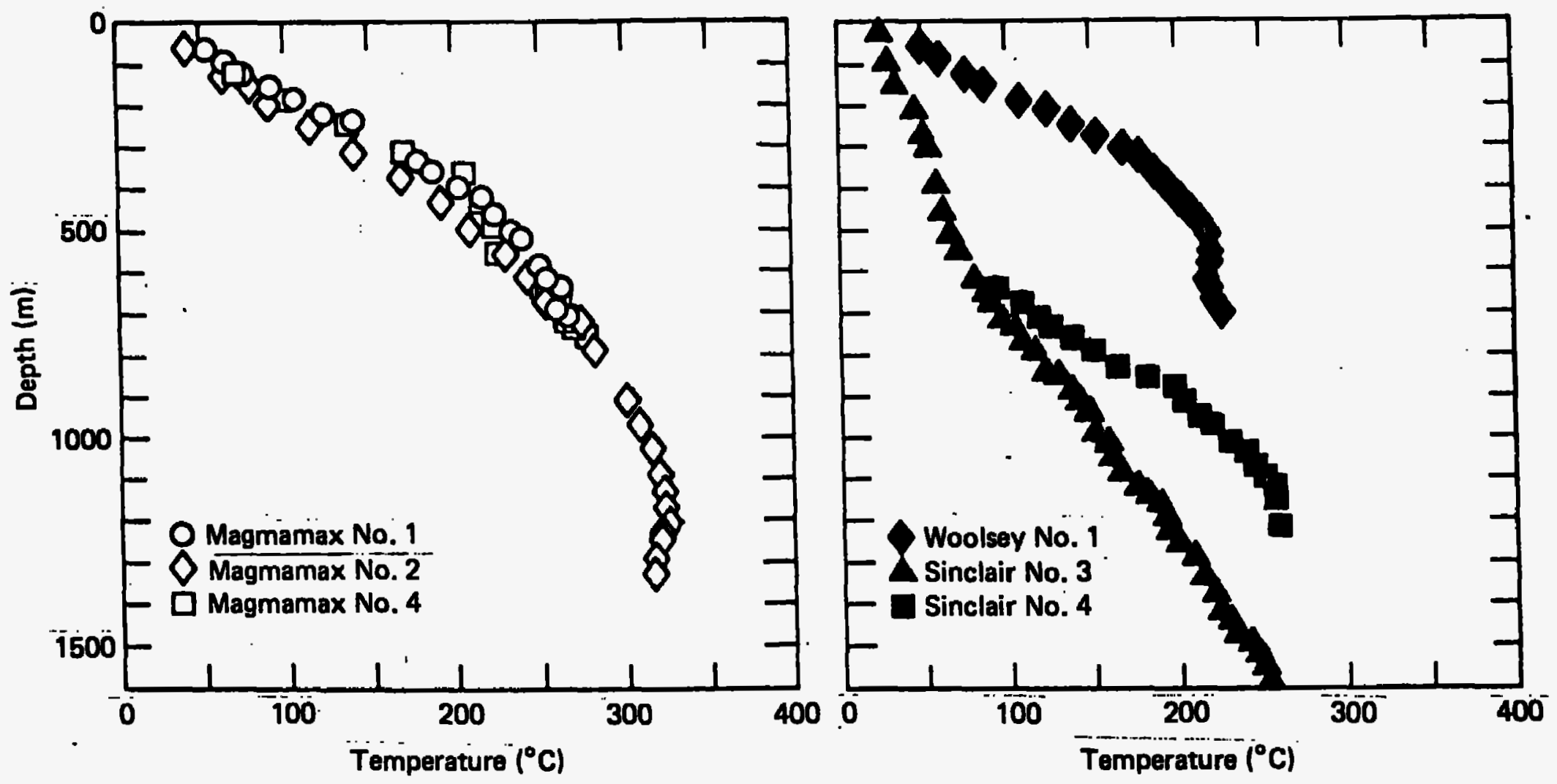

FIG. 3 - KASAMEYER 


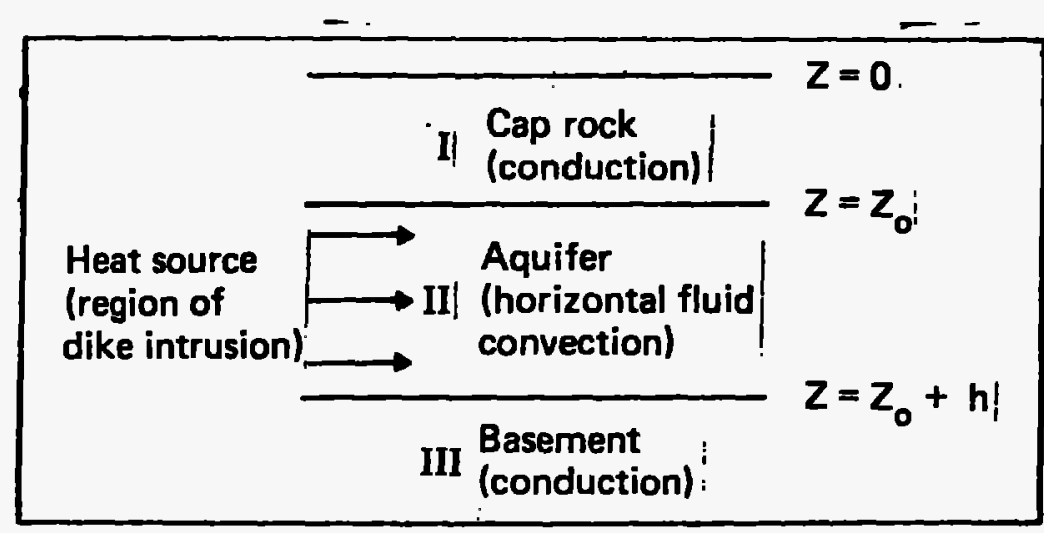

!

FIG. 4 - KASAMEYER 


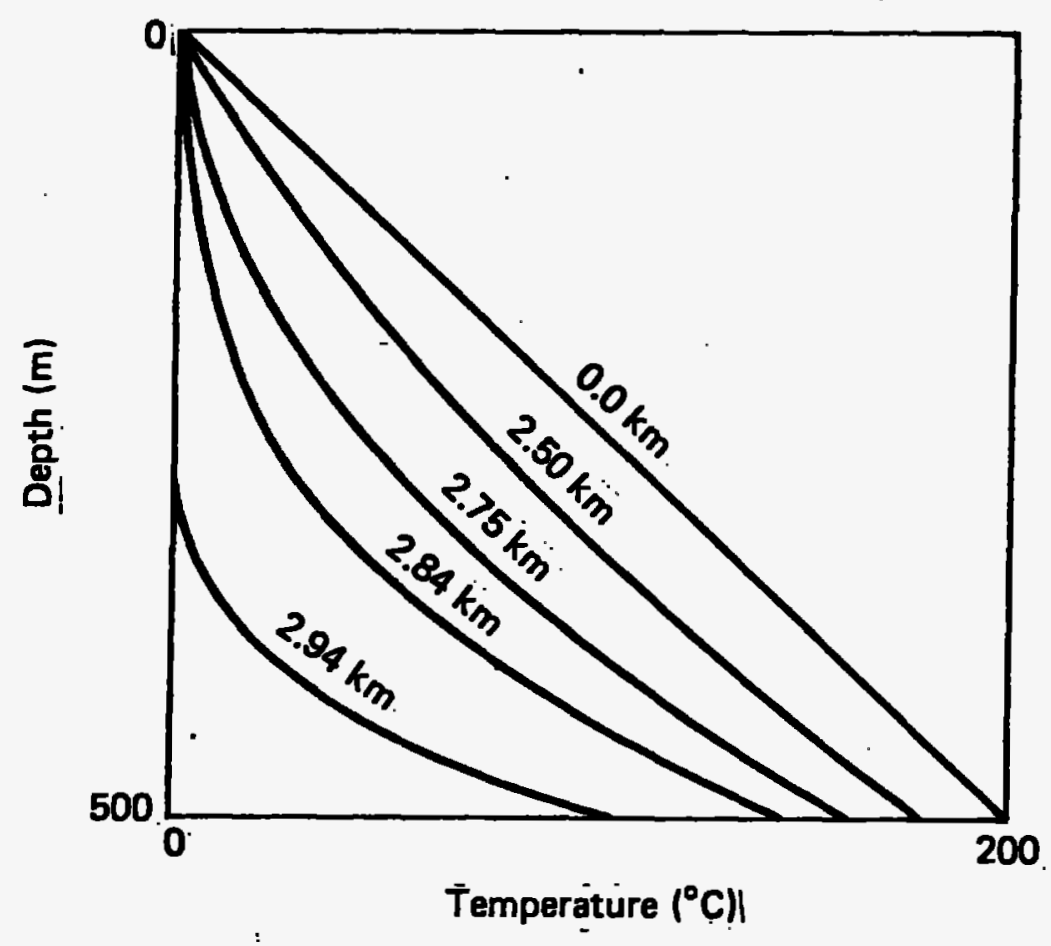

FIG. 5A - KASAMEYER 


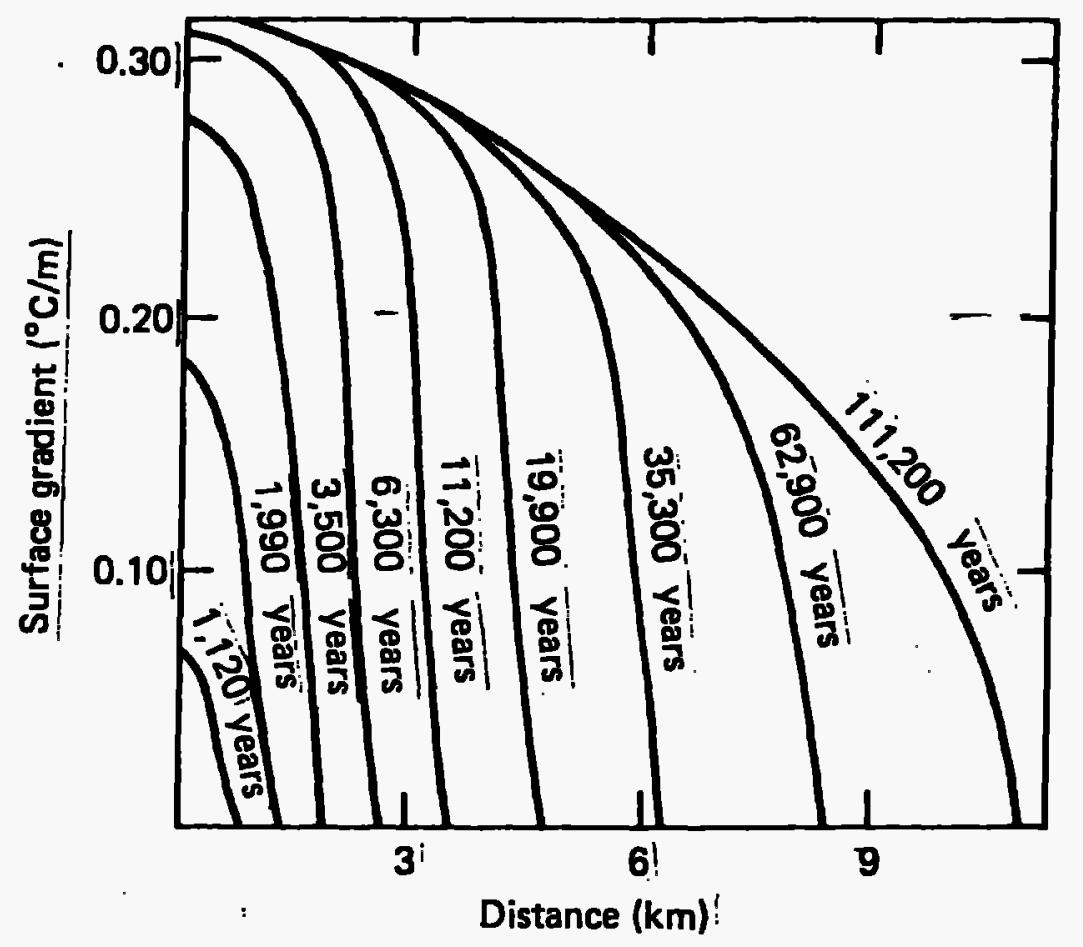

FIG. 5B - KASAMEYER 
$i$

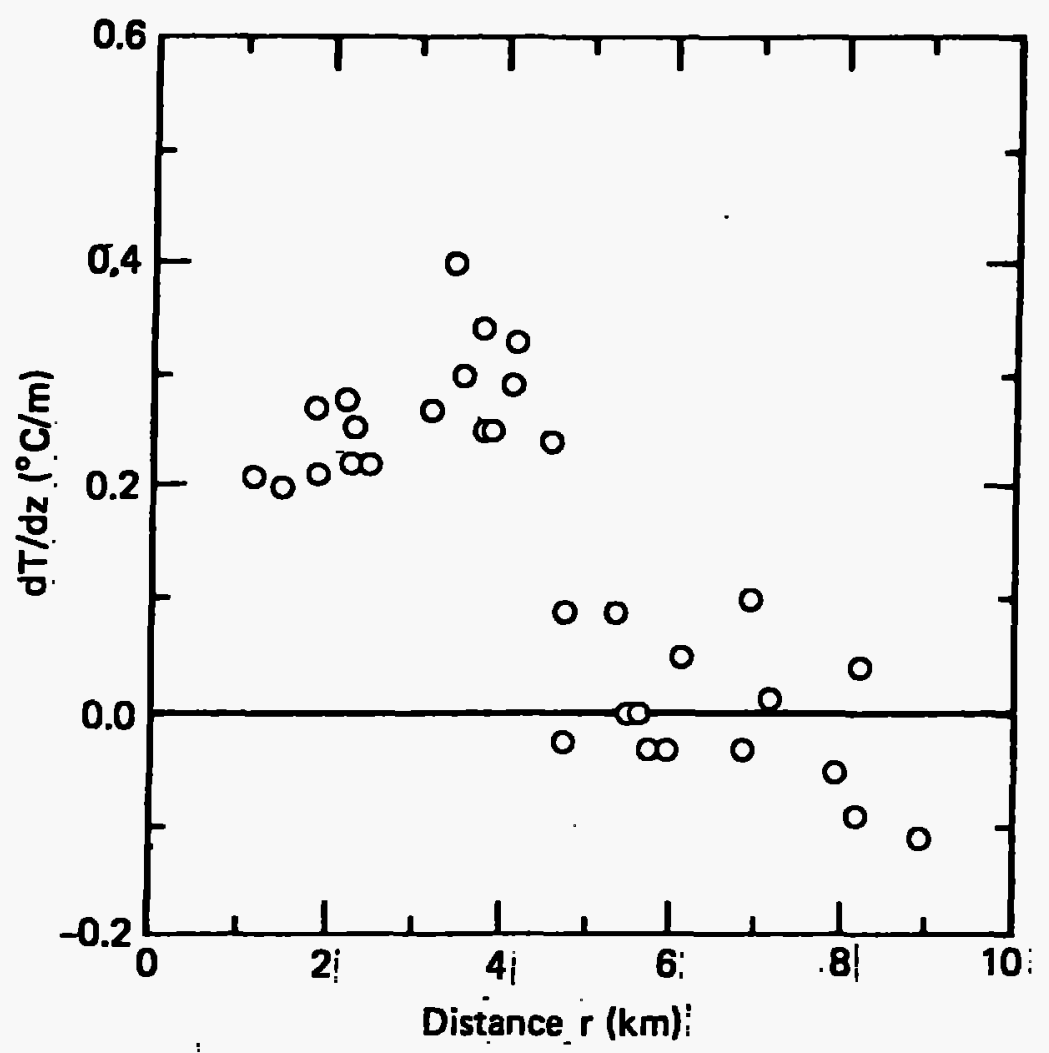

FIG. 6 - KASAMEYER 


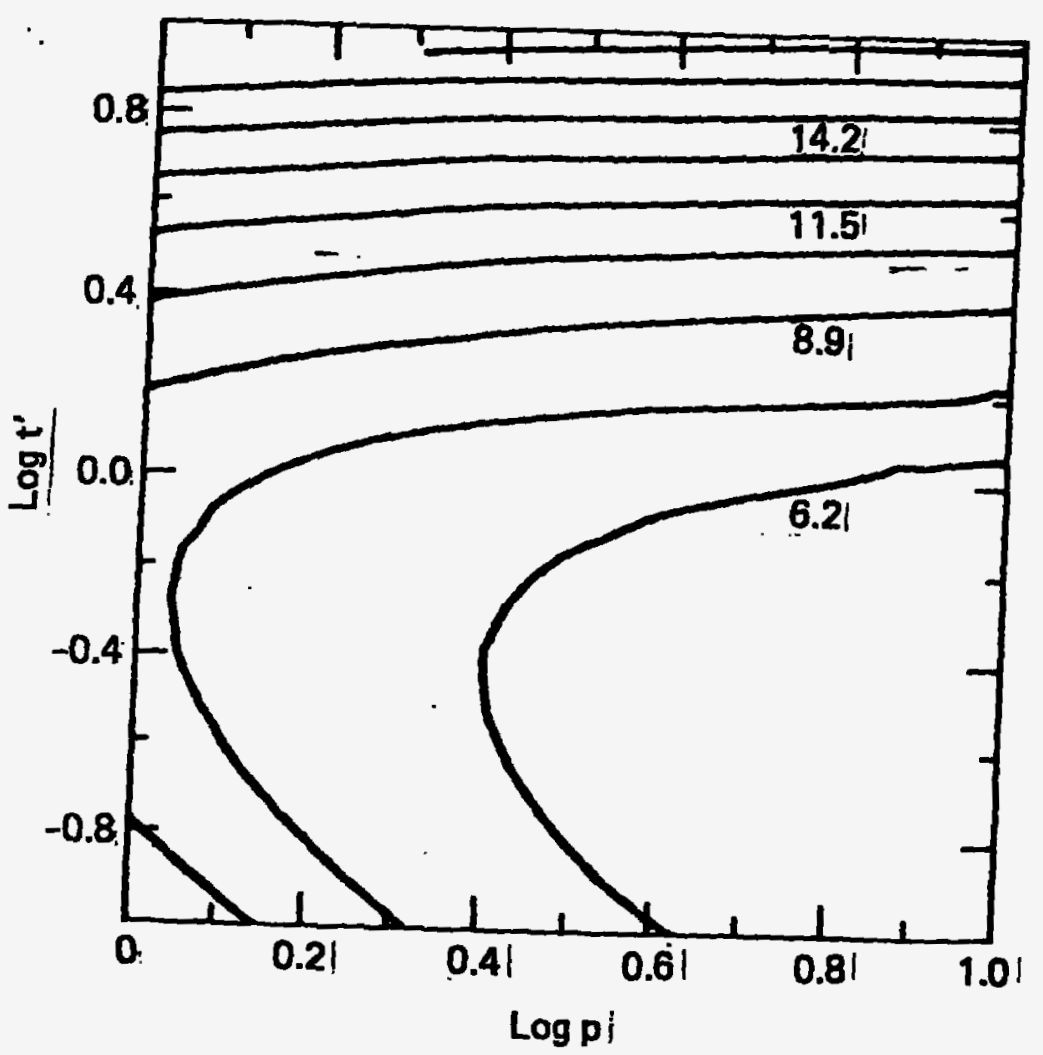

FIG. 7 - KASAMEYER 


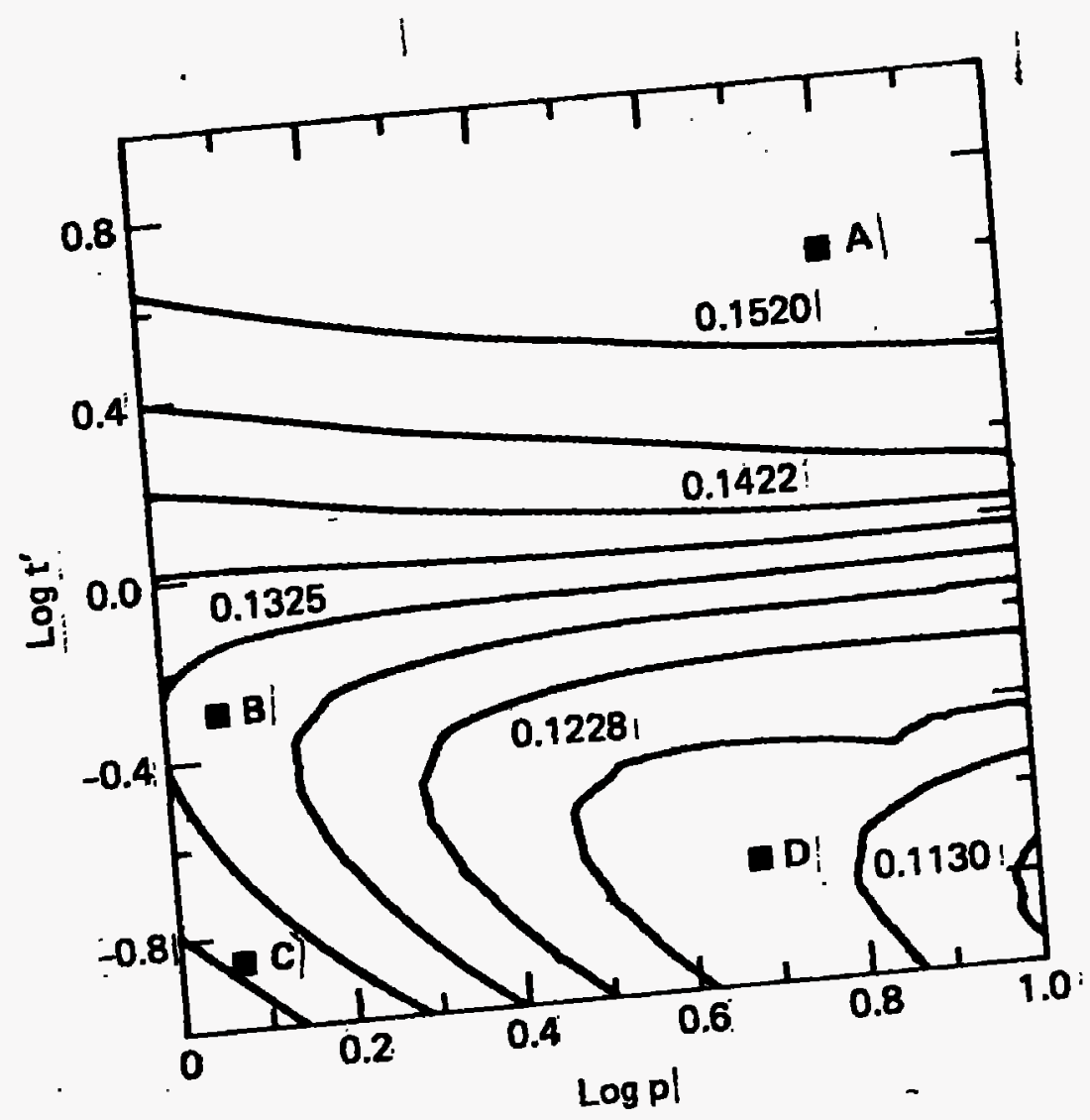

FIG. 8 - KASAMEYER 

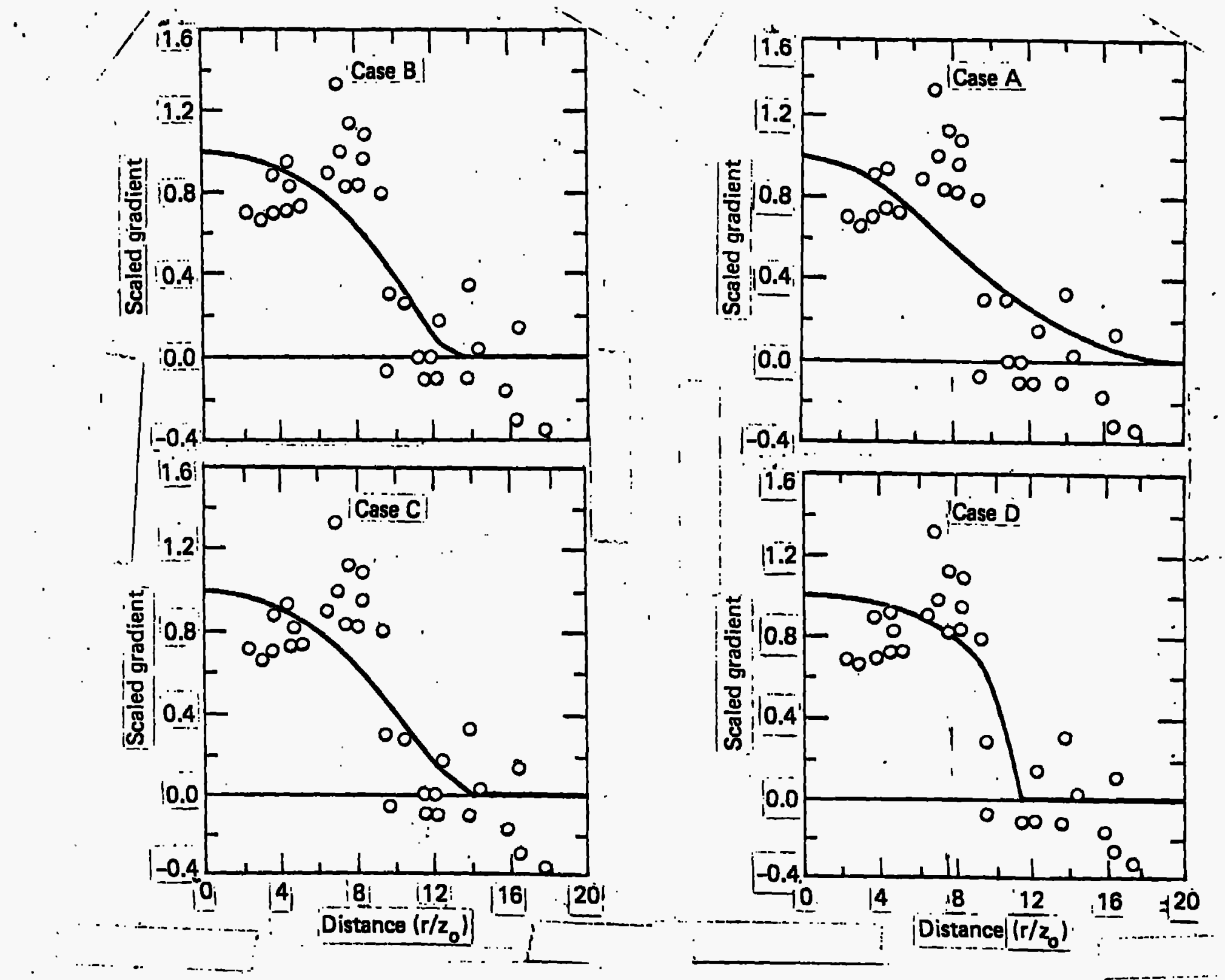

FIG.-9 - KASAMEYER 


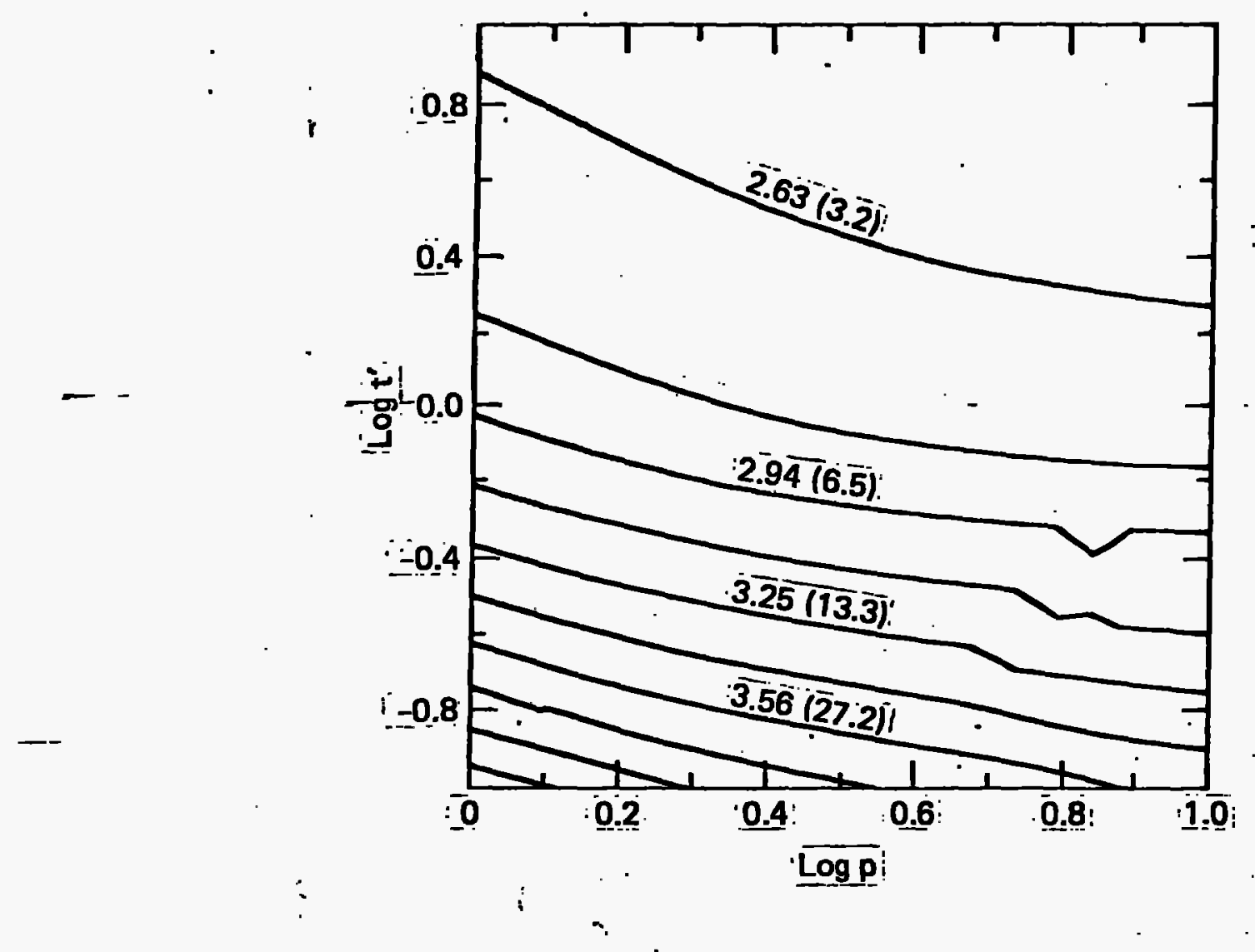

FIG. 10 - KASAMEYER 


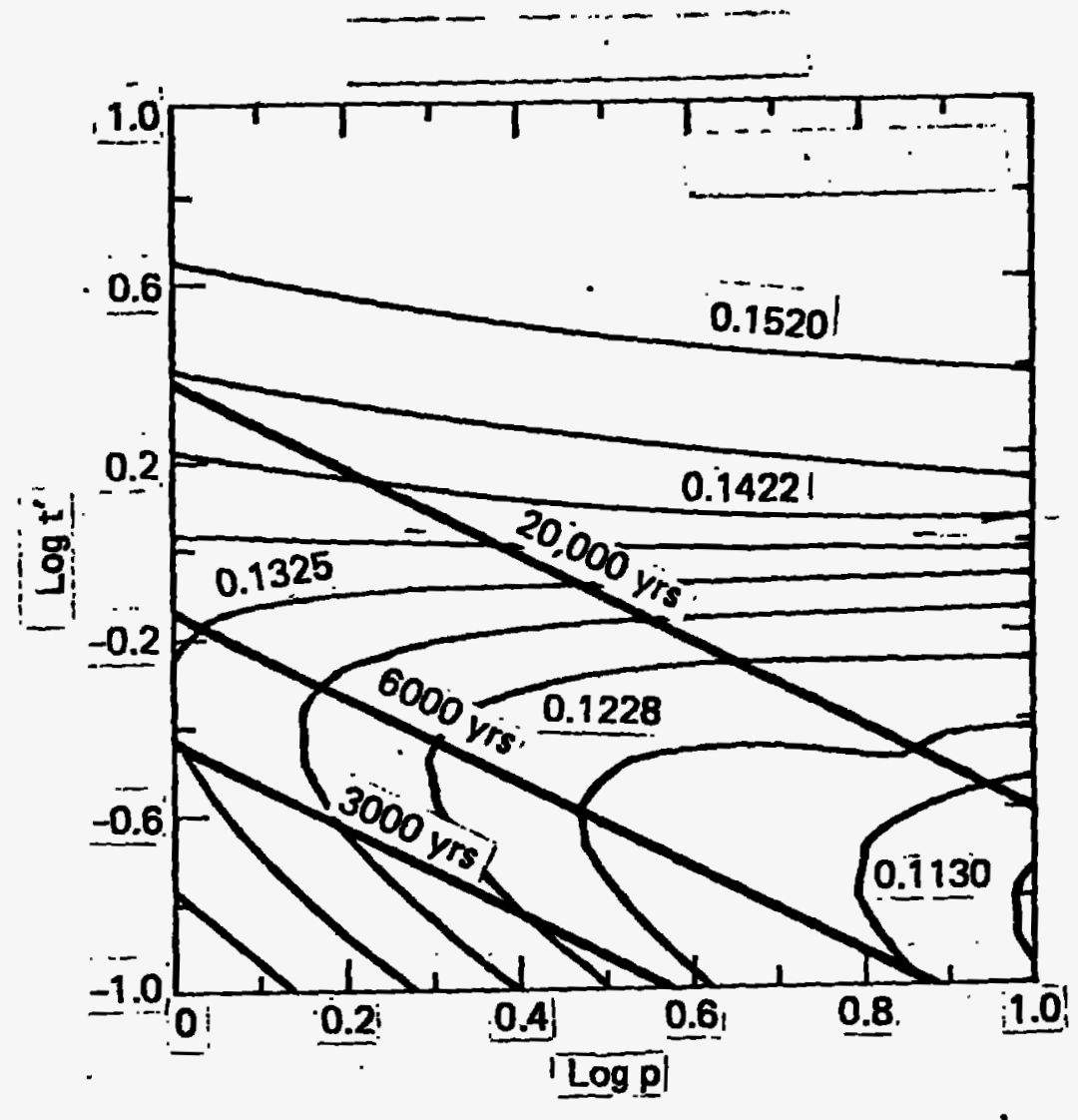

FIG. 11 - KASAMEYER 